\title{
RANCANG BANGUN SISTEM INFORMASI PENJUALAN BARANG PADA TOKO DISTRO BLACK OUTLET BERBASIS WEB
}

\author{
Qadhli Jafar Adrian'), Dedi Pramono ${ }^{2)}$ \\ ${ }^{1)}$ Sistem Informasi, Universitas Teknokrat Indonesia \\ Jl. H.ZA Pagaralam, No 9-11, Labuhanratu,Bandarlampung \\ Email : qadhli.adrian@teknokrat.ac.id ${ }^{1)}$,pension.dedi@gmail.com ${ }^{2)}$,
}

\begin{abstract}
Abstrak
Toko Distro Black Outlet merupakan usaha dagang yang bergerak dibidang fashion dan baru dibangun pada pertengahan tahun 2016 yang terletak di Jl. Kiwi No. 26 kelurahan Sidodadi Kecamatan Kedaton Bandar Lampung. Toko Distro Black Outlet menjual berbagai jenis dan tipe pakaian, jeans, dan nantinya akan menambah produk seperti aksesoris. Saat ini media promosi yang digunakan pada Toko Distro Black Outlet adalah dengan memasang banner di depan toko. Kemudian untuk mempromosikan produk baru menggunakan blackberry messenger yang hanya diketahui oleh kontak yang berteman dengan pihak Toko Distro Black Outlet. Permasalahannya informasi pemasaran produk baru tidak diketahui calon konsumen secara luas mengenai produk-produk pada Toko Distro Black Outlet. Akibat dari permasalahan yang ada, Toko Distro Black Outlet membutuhkan peningkatan pada pemasaran produk sehingga dapat menambah jumlah pelanggan dan pendapatan toko. Dengan menggunakan sistem e-marketing konsumen dapat dengan mudah mendapatkan informasi tentang produk-produk baru, mengenai model produk, harga produk, jumlah produk dan stok produk yang ada pada toko ini(Sumber: Toko Distro Black Outlet, 2016). Oleh karena itu untuk mengatasi permasalahan pemasaran pada Toko Distro Black Outlet, perlu dibuat E-Marketing, untuk menyediakan informasi produk. Penelitian ini bertujuan untuk membuat system pemasaran dengan pendekatan user experience design. Penelitian ini menggunakan perangkat CMS open cart.
\end{abstract}

Kata kunci: Pakaian, Distro, E-Marketing, Web-site.

\section{Pendahuluan}

Toko Distro Black Outlet merupakan usaha dagang yang bergerak dibidang fashion dan baru dibangun pada pertengahan tahun 2016 yang terletak di jl. Kiwi No. 26 kelurahan Sidodadi Kecamatan Kedaton Bandar Lampung. Toko Distro Black Outlet menjual berbagai jenis dan tipe pakaian, jeans, dan nantinya akan menambah produk seperti aksesoris.

E-Marketing (Elektronik Marketing) merupakan penggunaan atau pemanfaatan teknologi informasi dalam proses membuat, berkomunikasi, dan memberikan nilai (value) kepada pelanggan. E-Marketing mempengaruhi pemasaran tradisional dalam dua cara. Pertama, EMarketing meningkatkan efisiensi dalam fungsi pemasaran tradisional. Kedua, teknologi dari $e$ marketing mengubah banyak strategi pemasaran. Hasil perubahan dalam model bisnis baru ini dapat menambah nilai (value) pelanggan dan meningkatkan keuntungan perusahaan. E-Marketing juga merupakan sisi pemasaran dari e-commerce, yang terdiri dari usaha yang dilakukan oleh perusahaan untuk mengkomunikasikan sesuatu, mempromosikan, dan menjual barang dan jasa melalui internet.

Dengan sebuah website, perusahaan dapat memasarkan produk secara cepat untuk dapat dikenal oleh masyarakat luas mengenai penjelasan produk atau jasa yang lebih terperinci yang dapat membantu pihak perusahaan dalam menambah dan meningkatkan target penjualan, juga mempermudah pelanggan untuk mendapatkan informasi yang diinginkan (Raymond,2011). Akibat dari permasalahan yang ada, Toko Distro Black Outlet membutuhkan peningkatan pada pemasaran produk sehingga dapat menambah jumlah pelanggan dan pendapatan toko. Dengan menggunakan sistem $e$ marketing konsumen dapat dengan mudah mendapatkan informasi tentang produk-produk baru, mengenai model produk, harga produk, jumlah produk dan stok produk yang ada pada tokoToko Distro Black Outlet.

Oleh karena itu untuk mengatasi permasalahan pemasaran pada Toko Distro Black Outlet, perlu dibuat E-Marketing, untuk menyediakan informasi produk. Penelitian ini bertujuan untuk membuat system pemasaran dengan pendekatan user experience design. Penelitian ini menggunakan perangkat CMS open cart.

\section{Landasan Teori}

Menurut Al Bahra (2005:13) mendefinisikan sistem informasi adalah:

"Sistem informasi adalah suatu sistem yang dibuat oleh manusia yang terdiri dari komponen-komponen dalam organisasi untuk mencapai suatu tujuan yaitu menyajikan informasi". 
Menurut Jogiyanto, (2005:11) mendefinisikan sistem informasi adalah: "Sistem informasi adalah suatu sistem didalam suatu organisasi yang mempertemukan kebutuhan pengolahan transaksi harian, mendukung operasi, bersifat manajerial dan kegiatan strategi dari suatu organisasi yang menyediakan pihak luar tertentu dengan laporan-laporan yang diperlukan".

Sedangkan, menurut Ahmadi dan Hermawan (2013:186) mendefinisikan: "E-marketing adalah bagian dari $E$ Business yang memanfaatkan media elektronik untuk melakukan aktifitas marketing dalam upaya mencapai tujuan marketing."

Menurut Sulianta (2009:24) mendefinisikan:

"E-Marketing merupakan kombinasi aspek teknis internet, kreatifitas, desain, pengembangan, periklanan, dan penjualan".

Dapat disimpulkan bahwa E-Marketing merupakan aktifitas pemasaran barang atau jasa melalui media internet.

Ada beberapa tingkatan dalam pemanfaatan media elektronik, misalnya ada perusahaan yang sepenuhnya bergantung pada media elektronik, sementara perusahaan yang lain hanya memanfaatkan untuk tugas-tugas tertentu saja.

1. Banner Advertisement (iklan melalui banner) adalah file grafis yang dipasangkan pada website penyedia iklan.

2. Sponsorship (sponsor kerjasama)

3. Clsassified Listings (daftar produk terklasifikasi)

4. E-mail Marketing (pemasaran melalui e-mail)

5. Partnership/Affiliate Marketing (pemasaran metode afiliasi)

6. Search Engine Marketing (pemasaran menggunakan mesin pencari)

7. Social Netwroking (metode pemasaran menggunakan media sosial)

\section{Metode}

Menurut Rosa A.S, 2013 Prototype adalah :

"Satu versi dari sebuah sistem potensial yang memberikan ide bagi para pengembang dan calon pengguna, bagaimana sistem akan berfungsi dalam bentuk yang telah selesai”.

Proses pembuatan prototipe ini disebut prototyping, Dasar pemikirannya adalah membuat prototype secepat mungkin, bahkan dalam waktu semalam, lalu umpan balik dari pengguna yang akan memungkinkan prototype tersebut diperbaiki kembali dengan sangat cepat.

\section{Kesimpulan}

Berdasarkan hasil penelitian rancang bangun sistem informasi penjualan menggunakan e-marketing pada Toko Distro Black Outlet Kedaton , maka dapat ditarik simpulan sebagai berikut:

1. Menganalisa sistem informasi yang ada pada Toko Distro Black Outlet ialah melakukan observasi serta melakukan pengumpulan data dengan cara memberikan pertanyaan kepada pihak toko, masalah apa yang di hadapi pada saat tidak adanya penjualan barang berbasis website. Dengan adanya sistem informasi penjualan berbasis website diharapkan penjualan yang ada pada Toko Distro Black Outlet mengalami peningkatan.

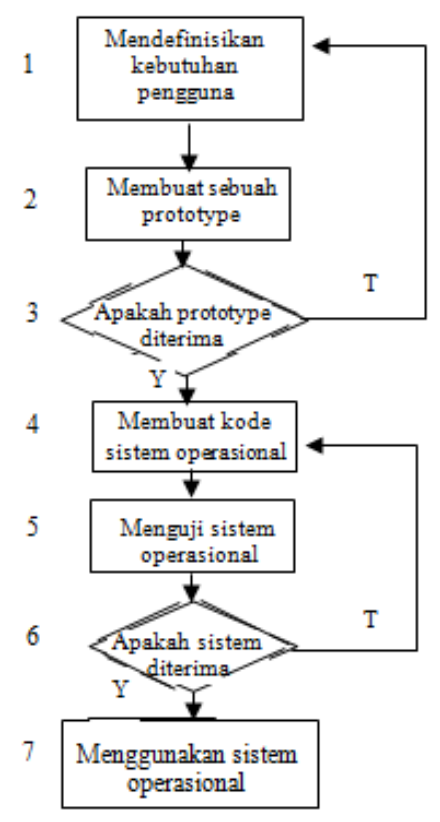

\section{Gambar 3.1 Pengembangan Prototype}

2. Merancang aplikasi e-marketing yang ada pada Toko Distro Black Outlet ialah menganalisa masalah yang ada pada toko, mengidentifikasi masalah yang ada, penentuan metode pengembangan sistem menggunakan Prototype, perancangan sistem yang digunakan UML, Framework yang digunakan ialah Laravel yang diharapkan dapat menarik perhatian calon konsumen.

\section{Saran}

Berdasarkan simpulan dari hasil penelitian yang telah diuraikan, maka saran yang dapat diberikan untuk pengembangan lebih lanjut dari pemasaran menggunakan e-marketing pada Toko Distro Black Outlet, antara lain: 
1. Memaksimalkan fungsi penggunaan aplikasi $e$ marketing melalui pengintegrasian aplikasi e-marketing dengan sistem-sistem lainnya yang dibutuhkan oleh Toko Distro Black Outlet.

2. Perlu dilakukan pelatihan kepada administrator sebelum aplikasi e-marketing ini digunakan agar memudahkan penggunaan aplikasi sebagai mana fungsinya.

3. Melakukan evaluasi terhadap aplikasi e-marketing agar dapat mengetahui kebutuhan pelanggan yang lebih lanjut sesuai dengan kebutuhan pelanggan.

\section{Daftar Pustaka}

Ahmadi, Chandra dan dadang Hermawan. 2013. EBusiness \& E-Commerce. Yogyakarta : CV. Andi Offset. (Diakses pada 14 September 2017), pada alamat web : https://aguslilinkecil.wordpress.com/tag/lan dasan-teori/page/2/

Al Fatta, Hanif. 2007.Analisis dan perancangan Sistem InformasiUntukKeunggulanBersaing Perusahaan dan Organisasi Modern. Andi. Yogyakarta.

Bin Ladjamudin, Al-Bahra, 2005, Analisa dan Desain Sistem Informasi, Graha Ilmu, Yogyakarta.

Jogiyanto, HM., 2005, Analisis Dan Desain Pendekatan Terstruktur Teori Dan Praktek Aplikasi Bisnis, Andi Offset, Yogyakarta.

Marwan, 1991, Dalam jurnal Ridwan Iskandar, SE. Pengertian Penjualan, (Diakases 20 September 2017).

Mcleod, Raymond dan George P. Schell, 2001,Dalam jurnal EIS Executive Information System, BABII2009, (Diakses Tanggal 18 April 2017)

Nugroho, Bunafit. 2005. Database Relasional Dengan MySQL. Yogyakarta: Andi.

Rosa A.S - M.Shalahuddin. 2011. Rekayasa Perangkat Lunak (Terstruktur dan Berrorientasi Objek), Modula, Bandung.

Suyanto, . 2007. MARKETING STRATEGY Top Brand Of Indonesia. Yogyakarta: Andi Offset. (Di akses pada tanggal 17 september 2017) 